\title{
Do large-scale wind farms affect air quality forecast? Modeling evidence in Northern China
}

$\mathrm{Si} \mathrm{Li}^{1,3}$, Tao Huang ${ }^{1 *}$, Jingyue $\mathrm{Mo}^{4}$, Jixiang $\mathrm{Li}^{1}$, Xiaodong Zhang ${ }^{1}$, Jiao Du ${ }^{1}$, Shu Tao ${ }^{2}$, Junfeng Liu ${ }^{2}$, Wanyanhan Jiang ${ }^{1}$, Lulu Lian ${ }^{1}$, Hong Gao ${ }^{1}$, Xiaoxuan Mao ${ }^{1}$, Yuan Zhao ${ }^{2}$, Jianmin $\mathrm{Ma}^{2,1}$ *

${ }^{1}$ Key Laboratory for Environmental Pollution Prediction and Control, Gansu Province; College of Earth and Environmental Sciences, Lanzhou University, Lanzhou 730000, P. R. China

${ }^{2}$ Laboratory for Earth Surface Processes, College of Urban and Environmental Sciences, Peking University, Beijing 100871, P. R. China

$10{ }^{3}$ College of Atmospheric Sciences, Lanzhou University, Lanzhou 730000, P. R. China

${ }^{4}$ Chinese Academy of Meteorological Sciences, Beijing 100000, P. R. China

*Corresponding to: Jianmin Ma (jmma@pku.edu.cn) and Tao Huang (huangt@1zu.edu.cn)

Abstract. Wind farms have been found to alter local and regional meteorology and climate. Here, we show that multiple large-scale wind farms might disturb air quality forecasts and affect $\mathrm{PM}_{2.5}$ air pollution. We explore the impact of large-scale wind farms on $\mathrm{PM}_{2.5}$ concentrations and forecasts in the Northern China Plain in winter and summer using a coupled weather forecast - atmospheric chemistry model (WRF-Chem). Modelling results reveal that the large-scale wind farms decrease $\mathrm{PM}_{2.5}$ levels within the wind farms and increase $\mathrm{PM}_{2.5}$ concentrations by $49 \%$ and $16 \%$ of the modelled monthly mean $\mathrm{PM}_{2.5}$ concentrations in proximate areas and regions hundreds of kilometres downstream. The wind farm-forced changes in $\mathrm{PM}_{2.5}$ are more evident in the simulated hourly $\mathrm{PM}_{2.5}$ concentrations. The model sensitivity studies reveal that hourly concentration fractions in winter induced by wind farms vary from $-40 \%$ to $250 \%$ in nearby and distant downstream regions and metropolises, comparing with the cases without the wind farms. The impact of wind farms on modeled $\mathrm{PM}_{2.5}$ during the nighttime is stronger than that in the daytime. Our results suggested that the wind farm perturbed changes in $\mathrm{PM}_{2.5}$ should not be overlooked because such changes might affect air quality forecast on an hourly basis, particularly in heavily contaminated Beijing-Tianjin-Hebei region by $\mathrm{PM}_{2.5}$.

\section{Introduction}

To reduce the emissions of greenhouse gases and air pollutants that resulted from fossil fuel combustion during the course of industrialization and urbanization, China has launched and set a low- 

energy technologies and has rapidly developed (Mo et al., 2017; McElroy et al., 2009). According to the Thirteenth Five-Year Plan issued by the Chinese National Energy Administration (CNEA, 2016), wind power has become the third largest power source in China after coal and hydroelectric power. In 2017, the total installed capacity of wind power in China reached $188 \mathrm{GW}$. Presently, there are nine 10-million $\mathrm{kW}$ class giant wind power bases in northern China, extending from Xinjiang in the west to northeast China. By the end of 2020, the total installed capacity of wind power will reach $210 \mathrm{GW}$, which will account for $6 \%$ of the country's total power generation (CNEA, 2016).

Large-scale wind farms can alter the turbulence field near an underlying surface by changing the surface roughness lengths and spinning wind turbine rotors. Extensive field measurement and modelling studies have revealed that wind turbines could significantly reduce wind speed at the wind turbine hub height within and downwind of wind farms and generate turbulence in turbine wakes (Baidya Roy, 2004; Christiansen and Hasager, 2005; Fitch et al., 2012). The increasing turbulent strength and activities induced by wind turbines cause nocturnal land surface temperature warming, enhance the vertical mixing of momentum, heat, moisture and other scalars such as air pollutants, and increase the boundary-layer height (Porté-Agel et al., 2014; Li et al., 2018; Fitch et al., 2013; Baidya Roy and Traiteur, 2010; Frandsen et al., 2006). Satellite synthetic aperture radar (SAR) has discerned a reduction in the mean wind speed of $8-9 \%$ in a giant wind farm (Christiansen and Hasager, 2005; Jimenez et al., 2015). The large-scale wind farms also exert dynamic and thermodynamic impacts on downstream areas via a "downstream impact” (Sun et al., 2018; Barrie and Kirk-Davidoff, 2010) and wake turbulence (Fitch et al., 2012).

The present study assesses the wind farm-induced changes in air pollutant redistribution and forecasts over all of northern China, where many giant- and large-scale wind farms have been built in the past two decades. Figure 1 illustrates these wind farms in northern China. As seen, intensive wind farms are located in Inner Mongolia and northern Hebei Province to the north of the Northern China Plain (NCP), including Beijing-Tianjin-Hebei, one of the regions in China and the globe most heavily polluted by $\mathrm{PM}_{2.5}$ and surface ozone $\left(\mathrm{O}_{3}\right)$ due to rapid industrialization and urbanization in the last three decades and the large capacity of the steel and energy industries in this region (Lu et al., 2018; Tao et al., 2017). Although wind energy plays an increasingly important role in the sustainable development and reduction of air pollutant emissions, it is not clear if and to what extent these large-scale wind farms (hereafter referred to as the wind farm chain (WFC) in northern China) could disturb the cycling, fate, 

perturbations of atmospheric transport of air contaminants induced by WFC could potentially affect regional air quality forecasts and the effectiveness of air pollution mitigation measures.

\section{Materials and Methods}

\subsection{Model configuration}

Figure 1 illustrates the nested model domain and the major large-scale wind farms (WFC) in northern China, highlighted by red colour shading. In particular, the WFC is located upstream of the NCP subject to the East Asia winter monsoon featured by prevailing westerly and northerly winds (Figure S1a) or downstream subject to the East Asia summer monsoon with prevailing southeasterly winds (Figure S1b). The nested model domain in the Lambert projection (Bossioli et al., 2016) was set with the outer domain (d01) covering northern China, extending from $88^{\circ}$ to $132^{\circ} \mathrm{E}$ and from $29^{\circ}$ to $50^{\circ} \mathrm{N}$ at a resolution of $50 \mathrm{~km} \times 50 \mathrm{~km}$. The inner domain (d02) with a resolution of $10 \mathrm{~km} \times 10 \mathrm{~km}$, covers a large area of Inner Mongolia, the NCP, and its surroundings. The total number of wind turbines in the outer domain (northern China, Figure 1) was approximately 81,000. Considering the nominal power of each turbine as $1.5 \mathrm{MW}$, these wind turbines yield the total power capacity of $121,500 \mathrm{MW}$ in northern Council (GWEC), 2017). According to the GWEC statistics, the power capacity in northern China's windfarms was $72 \%$ of its total in entire China but this percentage decreased in 2016 due to increasing wind abandoning rate in northern China in 2016. It is noted that the $10 \mathrm{~km} \times 10 \mathrm{~km}$ horizontal resolution is greater than the distance between wind turbines in the WFC. In previous modelling studies for the effect of wind farms on local meteorology, some investigators set 1-3 km horizontal spacing for a single wind farm (Fitch et al., 2012; Baidya Roy et al., 2004). For multiple large-scale wind farms, however, the model horizontal resolutions were chosen as several ten kilometres (Baidya Roy et al., 2010; Vautard et al., 2013; Sun et al., 2018). In the evaluation of wind farm parameterization in WRF model, Lee and Lundquist (2017) found that WRF performance did not depend on the number of wind turbines per model grid cell and array of wind turbines. In our case, the $10 \mathrm{~km}$ spatial resolution could be appropriate with the wind farm parameterization schemes as will be elaborated below.

The coupled weather forecast and atmospheric chemistry model WRF-Chem (version 3.8.1) was 
applied in our numerical investigations. There are 29 vertical model levels, with the top of the model atmosphere at $50 \mathrm{hPa}$. To better simulate the effects of a wind farm on the ABL and air pollutants, higher vertical resolutions within the atmospheric boundary layer (ABL) and the surface boundary layer (SBL) (approximately 5, 10, 50, 80, 100, 120,180, $300 \mathrm{~m}$, and so on) were adopted in the present study. The main physical parameterization options implemented here are presented in Table S1. The chemical mechanism used MOZART Chemistry with the MOSAIC 4-bin aerosol scheme using the KPP library (Ackermann et al., 1998; Borbon et al., 2013). National Center for Environmental Prediction (NCEP) reanalysis on a spatial resolution of $1^{\circ} \times 1^{\circ}$ latitude/longitude (https://www.esrl.noaa.gov/psd/data/gridded/reanalysis). The anthropogenic emissions used the MIX regional emission inventory (Li et al., 2017). Measured hourly winds and air temperature data at the observational stations in the inner model domain (Figure 1) for the evaluation of WRF modelled meteorology were collected from NOAA's National Climatic Data Center (NCDC), available at ftp://ftp.ncdc.noaa.gov/pub/data/noaa/isd-lite/.

The MIX emission inventory provides the gridded air emission data of $\mathrm{SO}_{2}, \mathrm{NO}_{\mathrm{x}}, \mathrm{CO}, \mathrm{NMVOC}$ (non-methane volatile organic compounds), $\mathrm{NH}_{3}, \mathrm{PM}_{10}, \mathrm{PM}_{2.5}, \mathrm{BC}, \mathrm{OC}$, and $\mathrm{CO}_{2}$ on a $0.25^{\circ} \times 0.25^{\circ}$ latitude/longitude resolution. The biogenic emissions were collected from Model of Emission of Gases and Aerosols from Nature (MEGAN) (Guenther et al., 2012) at a spatial resolution of approximately 1 $\mathrm{km}$. The emissions from biomass-burning were obtained from the Fire Inventory from NCAR (FINN) program at a resolution of $1 \mathrm{~km}$ (Wiedinmyer et al., 2011).

A contrast experiment, $t$ test formulation was used to test the significance of the modelled $\mathrm{PM}_{2.5}$ differences and fractions subject to the different model scenarios. Following Sun et al. (2018), the contrast experiment $t$ test is written as

$\mathrm{t}=\frac{\bar{d}}{S D / \sqrt{n}}$,

where $\bar{d}=\frac{1}{n} \sum_{i=1}^{n} \Delta P M_{2.5 i}, \Delta \mathrm{PM}_{2.5}$ is the hourly difference between two model scenarios, $n$ is the number of hours, and SD is the standard deviation. Note that the T-test was also applied in $\mathrm{PM}_{2.5}$ fractions between the WFC-related model scenarios and the BASE scenario but replaced the difference $\Delta \mathrm{PM}_{2.5}$ by $\mathrm{PM}_{2.5}$ fractions, calculated by, for example, $\left(\mathrm{C}_{\mathrm{Si}}-\mathrm{C}_{\mathrm{BASE}}\right) \times 100 / \mathrm{C}_{\mathrm{BASE}}$, where $\mathrm{C}_{\mathrm{Si}}$ is the $\mathrm{PM}_{2.5}$ concentrations from any of the WFC-related model scenario simulations and $\mathrm{C}_{\mathrm{BASE}}$ is the $\mathrm{PM}_{2.5}$ 
concentration from the BASE run.

\subsection{Wind farm parameterization}

Detailed information about the wind farms in northern China was collected from the China Certified maps, from which the locations of wind farms and wind turbines in northern China were collected

(Figure S2). Based on these data, we set the average hub-height of wind turbines at $96 \mathrm{~m}$, the blade (rotor) diameter as $113 \mathrm{~m}$, and the average wind turbine spacing at $678 \mathrm{~m}$ (approximately six times the rotor diameters). We used two wind farm parameterization schemes in our modelling. The first is the increased roughness length parameterization, which specifies the wind turbines by an increase of the surface roughness (Mo et al., 2017; Keith et al., 2004; Ivanova and Nadyozhina, 2000). This parameterization scheme calculates the aerodynamic roughness length $Z_{0}(\mathrm{~m})$ of a wind farm, defined by as (Lettau, 1969): $Z_{0}=0.5 h^{*} \frac{s}{s}$, where $h^{*}$ is the average vertical extent (m) or hub height for wind turbines and $s$ is the silhouette area $\left(\mathrm{km}^{2}\right)$ of the average obstacle or the rotating area for wind turbine blades. $S$ is the density of roughness elements, calculated by $S=A / n$, where $A$ is the total area occupied by obstacles $\left(\mathrm{km}^{2}\right)$ and $n$ the total number of obstacles. As aforementioned, the wind turbine spacing is set as six times the diameter of the wind turbine rotor. By setting s and $S$ as $0.01 \mathrm{~km}^{2}$ and $0.46 \mathrm{~km}^{2}$, we obtained the roughness length $\mathrm{Z}_{0}$ of $1.04 \mathrm{~m}$. This method has the advantages of simplicity and accuracy in representing the wind turbines (Wieringa, 1993; Petersen, 1997).

The second scheme, developed by Fitch et al. (2012), considers the wind turbines as a momentum sink within the turbine rotor area, which transforms kinetic energy (KE) into electricity and turbulent kinetic energy $\left(\mathrm{TKE}, \mathrm{m}^{2} \mathrm{~s}^{-2}\right.$ ). This scheme extracts the total fraction of KE from the air utilizing a thrust coefficient $\mathrm{C}_{\mathrm{T}}$, which is turbine type dependent and the function of wind speed. A proportion $\mathrm{KE}$ is converted to electrical energy by a power coefficient $C_{P}$. The rest of KE is converted to TKE, defined by the TKE coefficient $\mathrm{C}_{\mathrm{TKE}}=\mathrm{C}_{\mathrm{T}}-\mathrm{C}_{\mathrm{P}}$. The $\mathrm{C}_{\mathrm{T}}$ and $\mathrm{C}_{\mathrm{P}}$ can be taken from the turbine manufacturers. The WRF model implements the Fitch scheme (Fich et al., 2012, 2015; Yuan et al., 2017) which accounts for the effects of local wind drag on wind-energy extraction and power estimation (Lee and Lundquist, 2017). This scheme has been extensively applied in windfarm-meteorology interactive modelling using WRF 
Mo et al., 2017; Yuan et al., 2017; and Sun et al., 2018), and was also adopted here with a standing minimal thrust coefficient of 0.16. However, Volker et al. (2012) have reported that Fitch-scheme estimated thrust applied to the flow was overestimated by almost one order of magnitude and that the modeled TKE in the Fitch-scheme diffused the velocity deficit deep into the boundary layer, and caused unnaturally high positive velocity deficits at the lower boundary.

If the turbines are assumed to be oriented perpendicular to the wind flow, the drag force created by wind turbines is defined by:

$F_{\text {drag }}=\frac{1}{2} C_{T} \rho V^{2} A$

where $\rho$ is the air density, $A=(\pi / 4) D^{2}$ is the cross sectional rotor area (D is the diameter of the turbine blades), and $\mathrm{V}(\mathrm{u}, \mathrm{v})$ is the horizontal velocity.

The rate of loss for KE from the air subject to a wind turbine reads:

$\frac{\partial K E_{d r a g}}{\partial t}=-\frac{1}{2} C_{T} \rho V^{3} A$

The electric energy extracted from KE is defined by:

$\frac{\partial P}{\partial t}=\frac{1}{2} C_{P} \rho V^{3} A$

and the TKE extracted from the rest of KE is given by:

$\frac{\partial T K E}{\partial t}=\frac{1}{2} C_{T K E} \rho V^{3} A$

where the nominal power of a turbine is taken as $1.5 \mathrm{MW}$.

To examine the sensitivities of air quality in the NCP to WFC, we conducted extensive model simulations of $\mathrm{PM}_{2.5}$ in the NCP subject to four model scenarios (Table S2). The first model scenario is the control run (scenario 1, S1), in which the WFC was not taken into consideration, hereafter referred to as the BASE or no-WFC simulations. The second and third model scenarios used the surface roughness length parameterization scheme (referred to as the SRL run, S2) and the drag force parameterization (referred to as the DFP run, S3). Considering the future wind farm development in northern China, in the fourth model scenario we projected a double area of WFC with the drag force parameterization from the current wind farm area as shown in Figure 1 (referred to as the DOU run, S4). WRF-Chem was run for January and July 2016 to examine the responses of $\mathrm{PM}_{2.5}$ to different setups of the model scenarios under typical winter and summer atmospheric circulations.

2.3 Model evaluation 
Monitored $\mathrm{PM}_{2.5}$ concentration data at the selected locations in January and July 2016 were used to sampling sites in the model evaluation, collected from the national air quality automatic monitoring stations in China (http://106.37.208.233:20035/), including Beijing, Chengde, Hingdan, Siping, and Guyuan. Detailed model evaluations against the monitoring data at these sampling sites are presented in Supporting Information (SI) Text 1.1, Figures S3-S5, Tables S3-S5. The WRF predicted winds and temperature were also evaluated against measured data. Results are presented in SI Text 1.2, Figures S6-

S9, and Tables S6-S11.

\section{Results}

\subsection{WFC disturbed hourly and daily $\mathbf{P M}_{2.5}$ in winter}

Figure S10a shows WRF-Chem-simulated monthly averaged daily air concentrations of $\mathrm{PM}_{2.5}$ from the BASE run (S1, Methods) at the lowest model level ( $\sim 5 \mathrm{~m}$ above the ground surface) across the model domain in January 2016. High concentrations can be observed in the NCP due to strong emissions of $\mathrm{PM}_{2.5}$ precursors (e.g., sulphur dioxide, $\mathrm{SO}_{2}$, and nitrogen oxide, $\mathrm{NO}_{\mathrm{x}}$ ) in these heavy industrial regions featured by steel, energy, and cement industries (Zhao et al., 2013; Xu et al., 2016; Wang et al., 2018).

Figure S10b-d illustrates the concentration differences between model scenarios 2-4 simulations and the BASE run (S1) results. Marked positive $\mathrm{PM}_{2.5}$ differences occur in central and northeastern Hebei Province from all three model scenario runs. The maximum $\mathrm{PM}_{2.5}$ difference was as high as $14 \mu \mathrm{g} \mathrm{m}^{-3}$ in the highly polluted Beijing-Tianjin-Hebei region, which was a maximum $10 \%$ increase in monthly mean $\mathrm{PM}_{2.5}$ concentration. This is also illustrated by the fraction of mean $\mathrm{PM}_{2.5}$ concentrations from the SRL (S2) and DFP (S3) runs to that from the BASE run (S1) in Figure $2 \mathbf{a}$ and $\mathbf{2 b}$, estimated by $f_{i}=\left(\mathrm{C}_{\mathrm{Si}}-\mathrm{C}_{\mathrm{BASE}}\right)$ $\times 100 / \mathrm{C}_{\mathrm{BASE}}$, where $\mathrm{C}_{\mathrm{Si}}$ is monthly mean $\mathrm{PM}_{2.5}$ concentration from the SRL ( $\left.\mathrm{i}=1\right)$ and $\mathrm{DFP}(\mathrm{i}=2)$ runs and $\mathrm{C}_{\mathrm{BASE}}$ is $\mathrm{PM}_{2.5}$ concentration from the BASE run, respectively. The results from the two wind farm parameterization schemes do not exhibit significant differences in simulated $\mathrm{PM}_{2.5}$ concentrations. The negative concentration fractions can be identified in Inner Mongolia in the northern WFC. For the DOU run, doubling the wind farm installation expands the area with positive concentration differences (Figure S10d), which extends from Beijing-Tianjin-Hebei to Shandong Province, although the values of the positive fractions were larger than those from the SRL and DFP runs (Figure 2a, 2b). It is also evident 
that the doubling of the wind farm area (DOU run) resulted in the expansion of areas with negative $\mathrm{PM}_{2.5}$ fractions (Figure 2c) compared with the SRL and DFP simulations (Figure 2a and 2b), which predicts lower $\mathrm{PM}_{2.5}$ concentrations in the vicinity of the WFC. However, as shown in Figure S11, which scenarios in Zhangjiakou near the WFC, doubling WFC area enhances $\mathrm{PM}_{2.5}$ concentrations by $30 \%$ $150 \%$, which generally indicates a positive response of $\mathrm{PM}_{2.5}$ to the expansion of wind farm areas.

Figure S12 illustrates WRF model-simulated mean wind speed differences between the WFCrelated scenarios and the BASE scenario at the hub height averaged over January 2016. It has been known that wind turbines act to extract momentum from the atmosphere and produce large wind speed deficits within and around wind farms at the hub-height level. Such deficits can be clearly identified from wind speed differences between the WFC-related simulations (SRL, DFP, DOU) and the BASE run. Negative differences of the mean wind speeds with and without considering wind farms occur within and around wind farms (Figure S12a-c), which indicates declining wind speeds. The weak wind speeds are significantly associated with the locations of the WFC, as shown in Figure S12. The maximum wind speed reduction reached $6 \mathrm{~m} \mathrm{~s}^{-1}$ within the wind farm, which suggests a $40 \%$ reduction of wind speed. The deficit of wind speeds gradually diminishes in the downstream (south) of the WFC. Since the lower wind speeds result in weak atmospheric transport and diffusion of air pollutants, the simulated $\mathrm{PM}_{2.5}$ tends to increase in the downstream of the WFC, as shown in Figure S10b-d and Figure 2a-c. Mo et al. (2017) proposed an edge effect of a large-scale wind farm on the spatial distribution of air pollutants within and around the wind farm, featured by a higher concentration at the immediate upwind and border region of the wind farm. This edge effect was attributed to the changes in wind speed and turbulence intensity driven by the rotation of the rotor blades and the increase of the effective surface roughness length within the wind farm, which led to a step change from the smooth (upstream region) to the rough (wind farm) underlying surface (Mo et al., 2017; Barrie and Kirk-Davidoff, 2010). In the downstream region of a wind farm, the air pollutant concentration tends to decrease, induced by increasing wind speed due to the rough-to-smooth underlying surface transition and recovered momentum in the downstream of the wind farm from the lost momentum within the wind farm. However, due to relatively lower friction velocity and weak turbulence over the smooth surface, the decreasing turbulent mixing could reduce 
concentrations in downstream (Figure S10 and Figure 2).

Figure 3a displays the fractions of WRF-Chem-modelled hourly $\mathrm{PM}_{2.5}$ concentrations $\left(\mu \mathrm{g} \mathrm{m}^{-3}\right)$ in January 2016 from the SRL simulation to that from the BASE run in northeast (NHB) and central Hebei regions and cities, northeast Hebei and Zhangjiakou are proximate to the WFC, central Hebei is a mostly contaminated region by $\mathrm{PM}_{2.5}$, and Beijing and Tianjin are two megacities that were also subject to severe $\mathrm{PM}_{2.5}$ contamination in 2016. Strong perturbations of $\mathrm{PM}_{2.5}$ induced by the WFC on an hourly basis can be discerned in NHB, with the maximum fraction of up to $250 \%$ (green dashed line), followed by ZJK with the maximum fraction of approximately $180 \%$ (blue dashed line), which confirms that the stronger influences of the WFC on $\mathrm{PM}_{2.5}$ distribution occurred in its proximate locations. Large fractions of modelled $\mathrm{PM}_{2.5}$ hourly concentrations can also be identified in central Hebei (CHB), with the maximum $\mathrm{PM}_{2.5}$ fraction exceeding $170 \%$ on January 12, 2016 (purple dashed line, Figure 3a). In the two megacities of Beijing (red solid line) and Tianjin (black dotted line), the WFC-disturbed maximum $\mathrm{PM}_{2.5}$ hourly concentration fractions also ranged from $-24 \%$ to $165 \%$, and in many occasions, the concentration fractions fluctuated by $\pm 30 \%$, which manifested marked concentration perturbations in these two megacities induced by the WFC, although the two megacities are 200-300 kilometres away from the WFC. The monthly average hourly concentration fractions were $49 \%$ for northeast Hebei, $16 \%$ for central Hebei, 5\% for Beijing, $0 \%$ for Tianjin, and 3\% for Zhangjiakou, which again shows significant responses of modelled $\mathrm{PM}_{2.5}$ perturbations to the WFC in downstream regions and cities. Different from positive and negative hourly concentration fluctuations, the monthly concentration fractions were positive in all selected regions and cities. The influences of the WFC on $\mathrm{PM}_{2.5}$ in Beijing (5\%) and Tianjin (0\%) were less significant on a monthly basis, potentially within a model error range. Although the $\mathrm{PM}_{2.5}$ hourly concentration fractions at Zhangjiakou showed large fluctuations next to the NHB, the monthly mean concentration fraction was small (Figure 3b). The large fractions of simulated $\mathrm{PM}_{2.5}$ hourly concentrations with and without the presence of the WFC seem to suggest that the WFC exerts a strong influence on hourly changes in downstream $\mathrm{PM}_{2.5}$ concentrations, which causes uncertainties in $\mathrm{PM}_{2.5}$ forecasts in these regions and cities. Such significant influence even extends to the monthly average $\mathrm{PM}_{2.5}$ concentrations by as much as $50 \%$.

Hourly or diurnal changes in local atmospheric circulation and wind and turbulence fields could play an important role in $\mathrm{PM}_{2.5}$ concentration fluctuations. We selected two cases in Zhangiiakou, with 
the maximum concentration fraction (192.7\%) at 0700 local standard time (LST) January 4, 2016 and the minimum concentration fraction $(-37.3 \%)$ at 1500 LST January 16,2016 , to examine the associations between fluctuations of the $\mathrm{PM}_{2.5}$ concentration fractions and local atmospheric circulation. Results are

illustrated in Figure 4, which illustrates the model-simulated fractions of $\mathrm{PM}_{2.5}$ concentration between the DFP and BASE model scenario simulations near the surface. Positive concentration fractions downstream of the WFC when the maximum concentration fraction occurred at 0700 LST on January 4, 2016 (Figure 3a) and minimum concentration fraction within and downstream of the WFC at 1500 LST in January 16, 2016, the time that the minimum $\mathrm{PM}_{2.5}$ fraction occurred (Figure 3a). We further examined the wind speed differences at the hub height in these two cases. Located in the winter monsoon regime, the northwesterly wind prevails over the model domain (Figure S1). In these two cases subject to the maximum and minimum $\mathrm{PM}_{2.5}$ concentration fractions, the modelling results show larger negative wind speed fractions (Figure 4d) within and around the WFC in the case of the minimum $\mathrm{PM}_{2.5}$ fractions that occurred at 1500 LST in January 16, 2016, which indicates a stronger wind speed deficit or decline in the presence of WFC compared with the no-WFC case (BASE scenario), whereas the smaller negative wind speed fractions occurred in the case with the maximum $\mathrm{PM}_{2.5}$ fraction (Figure 4c). The larger negative wind speed fraction in the minimum $\mathrm{PM}_{2.5}$ concentration fraction than that in the maximum $\mathrm{PM}_{2.5}$ concentration fraction was not expected because the decreasing wind speed should have resulted in higher $\mathrm{PM}_{2.5}$ concentration. We would thus expect positive $\mathrm{PM}_{2.5}$ concentration fraction in Figure $\mathbf{4 b}$.

Figure $4 \mathbf{c}$ and $\mathbf{4 d}$ also illustrate wind vectors superimposed with wind speed fractions, from which we could identify a southerly flow extending from the NCP to the WFC in the case of the maximum $\mathrm{PM}_{2.5}$ concentration fraction (Figure 4c), although the northwesterly wind prevails in the winter season in this region. This southerly flow could provide an atmospheric transport route delivering $\mathrm{PM}_{2.5}$ from the mostly contaminated NCP region to the WFC. However, in the case of the minimum $\mathrm{PM}_{2.5}$ fraction we can observe relatively strong northwesterly and northeasterly winds across the WFC, which do not favour the atmospheric transport of $\mathrm{PM}_{2.5}$ from the south of the WFC as the major source region of $\mathrm{PM}_{2.5}$ precursors. In this sense, the regional wind field plays a more important role than the WFC-perturbed wind field.

Figure $4 \mathbf{e}$ and $\mathbf{4 f}$ show the fractions of the simulated turbulent kinetic energy (TKE) $\left(\mathrm{m}^{2} \mathrm{~s}^{-2}\right)$ at the 
Comparing TKE fractions between the two cases, one can identify stronger fractions within and around the WFC on January 16, 2016 (Figure 4d), when the minimum $\mathrm{PM}_{2.5}$ concentration fraction occurred. Since wind turbine extracts energy from the atmosphere and creates turbulence in its wake, larger TKE occurs in the downwind region of the WFC, which enhances the vertical mixing of $\mathrm{PM}_{2.5}$ and thereby reduces $\mathrm{PM}_{2.5}$ levels near the surface. As a result, the larger negative $\mathrm{PM}_{2.5}$ concentration fraction corresponds to a greater positive TKE fraction, as shown in Figure $\mathbf{4 b}$ and $\mathbf{4 f}$. The downstream undershooting from the step changes in the surface roughness might also contribute to the declining $\mathrm{PM}_{2.5}$ or larger negative $\mathrm{PM}_{2.5}$ concentration fractions. Under the northerly wind regime, the rough-to-smooth underlying surface transition from the WFC to its downstream could increase wind speed and accelerate the southward transport of $\mathrm{PM}_{2.5}$, thus reducing $\mathrm{PM}_{2.5}$ concentration in the downstream region, as shown in Figure $4 \mathrm{~b}$ and $\mathbf{4 f}$.

\subsection{WFC disturbed hourly and daily $\mathbf{P M}_{2.5}$ in summer}

Figure 5 shows WRF-Chem-simulated monthly mean $\mathrm{PM}_{2.5}$ air concentrations in July 2016 in northern China and the mean concentration differences between the control model (BASE) run and SRL, DFP, and DOU model scenario runs in July 2016. Similar to the winter case, severe $\mathrm{PM}_{2.5}$ pollution occurred in the Beijing-Tianjin-Hebei area. Positive $\Delta \mathrm{PM}_{2.5}$ can be discerned in the south (downstream) of the WFC, which is more evident in the DFP scenario run (Figure 5c). Doubling the WFC seems not to significantly alter the monthly $\Delta \mathrm{PM}_{2.5}$ (Figure 5d). Note that positive $\Delta \mathrm{PM}_{2.5}$ can also be observed in the far south of the WFC such as in Shandong Province and over the coastal waters of the Bohai Sea and the Yellow Sea. It is not yet clear how the WFC could force increasing $\mathrm{PM}_{2.5}$ air concentrations in those places far distant from the WFC. A previous study has revealed that the perturbed weather response to a large wind farm array could extend to several thousand kilometres downstream (Barrie and KirkDavidoff, 2010). Overall, the monthly $\mathrm{PM}_{2.5}$ concentration fractions from the SRL, DFP, and DOU model runs to that of the control run are small. Compared with the January case (Figure 2), no statistically significant positive concentration fractions were identified in the downstream of the WFC in July. This is likely attributed to stronger local boundary layer circulation occurring in the summertime. Although the summer Asian monsoon is a primary summer atmospheric circulation pattern in the inner model domain, local weather conditions are often dominated by local atmospheric circulations driven by non- 
speed differences between three WFC runs and the BASE run in Figure S13 show smaller areas of negative mean wind differences in July than January, indicating that the wind deficits induced by the WFC in July is less significant than January. Differing from $\triangle T K E$ as shown in Figure $4 \mathbf{e}$ and $\mathbf{4 f}$ in January 2016, modelled $\triangle$ TKE fractions (\%) at the hub height between the DFP and BASE model scenario simulations at the time of the maximum $\mathrm{PM}_{2.5}$ fraction (0700 LST July 16, 2016) and minimum fraction (0900 LST July 14, 2016) do not illustrate marked increase within and around the WFC. Summer local circulation might disturb the WFC-induced changes in turbulence and wind speed.

Hourly and monthly concentration fractions of the SRL run to that of the control (BASE) run in the selected five regions and cities are illustrated in Figure 6. Compared with the winter case (Figure 3a), the hourly concentration fractions do not significantly fluctuate (Figure 6a), which suggests that during most of July, the WFC did not frequently disturb hourly changes in $\mathrm{PM}_{2.5}$ concentrations. However, we can still identify strong oscillations, with the maximum amplitude as high as $400 \%$ in the hourly $\mathrm{PM}_{2.5}$ concentrations fractions at 2100 LST July 15, 2016 in NHB and 1400 LST July 24, 2016 in ZJK, which is stronger than that in the wintertime. The monthly averaged concentration fractions are all positive in the five selected regions and cities (Figure 6b), with the highest fraction of $11.9 \%$ in ZJK, followed by $10.5 \%$ in NHB, $5.1 \%$ in Tianjin, $5 \%$ in Beijing, and $4.3 \%$ in CHB, which again indicates that the WFC increases $\mathrm{PM}_{2.5}$ concentrations in these places. As shown in Figure 6b, the prevailing wind in northern China in summer consists of mainly southerly and southeasterly winds under the East Asian summer monsoon regime. The wind direction alters more frequently in summer than in winter. The average wind deficit within the WFC is approximately $2 \mathrm{~m} \mathrm{~s}^{-1}$ and $1 \mathrm{~m} \mathrm{~s}^{-1}$ around the WFC. These wind speed deficits are much smaller than that in winter but are still visible, which likely results in weak fluctuations of the modelled $\mathrm{PM}_{2.5}$ concentrations.

\subsection{Daytime and nighttime PM2.5 perturbed by WFC}

Baidya Roy and Traiteur found that a wind farm exerted a significant impact on atmospheric stability and the development of the boundary layer over the wind farm, with obvious diurnal variations (Baidya Roy and Traiteur, 2010). Figure 7a and $\mathbf{7 b}$ display monthly average daytime and nighttime $\mathrm{PM}_{2.5}$ air concentrations in January 2016 across the model domain at 0700-1800 LST (daytime) and 1900-0600 LST (nighttime), respectively. Similar to Figure 2b, higher $\mathrm{PM}_{2.5}$ levels in both day and night were simulated in the Beijing-Tianjin-Hebei area as the major source region of $\mathrm{PM}_{2.5}$ precursors in China. A 

the daytime due to weak winds and stable boundary-layer conditions. Figure 7c-h illustrate the fractions of monthly mean $\mathrm{PM}_{2.5}$ concentrations $\left(\Delta \mathrm{PM}_{2.5}\right)$ between the WFC-related scenario runs (SRL, DFP, DOU) and the no-WFC scenario run (control run) during the daytime (Figure 7c-e) and the nighttime (Figure 7f-h), respectively. As shown, the WFC more strongly increases the mean $\mathrm{PM}_{2.5}$ concentrations, that the most significant changes in $\Delta \mathrm{PM}_{2.5}$ or increasing $\mathrm{PM}_{2.5}$ occur in the most severely $\mathrm{PM}_{2.5-}$ contaminated region in Beijing-Tianjin-Hebei in both daytime and nighttime, rather than in the immediate neighbouring region of the WFC.

\section{4 $\mathrm{PM}_{2.5}$ in projected WFC expansion}

The response of $\mathrm{PM}_{2.5}$ to the projected WFC expansion can be further elucidated by comparing the simulated $\mathrm{PM}_{2.5}$ concentration fractions between the DFP and DOU scenario runs and the BASE run in Zhangjiakou because the DOU run was performed using the same wind farm parameterization scheme as that of the DFP run (drag force parameterization) and Zhangjiakou is the city nearest to the WFC. Figure 8 displays the hourly time series of $\mathrm{PM}_{2.5}$ fractions of DOU (red dash line) and DFP (solid deep blue line) to the BASE simulations in Zhangjiakou in January 2016, estimated by $\left(\mathrm{PM}_{2.5 \mathrm{Dou}}{ }^{-}\right.$ $\left.\mathrm{PM}_{2.5 \mathrm{BASE}}\right) / \mathrm{PM}_{2.5 \mathrm{BASE}} \times 100$ (also applicable for the DFP case by replacing $\mathrm{PM}_{2.5 \mathrm{DOU}}$ by $\mathrm{PM}_{2.5 \mathrm{DFP}}$ ), where $\mathrm{PM}_{2.5 \mathrm{DOU}}, \mathrm{PM}_{2.5 \mathrm{DFP}}$, and $\mathrm{PM}_{2.5 \mathrm{BASE}}$ are the $\mathrm{PM}_{2.5}$ concentrations from the three model scenario simulations. In most cases, we observed large positive concentration fractions between the DOU and BASE runs, which indicates that doubling the WFC installation increases $\mathrm{PM}_{2.5}$ levels in Zhangjiakou. In many cases the concentration fractions between the DOU and BASE runs are considerably greater than those between the DFP and BASE runs. Note also that the fractions between the DOU and BASE simulations are often positive, whereas the DFP to BASE fractions are negative, which suggests that doubling the WFC turns the decreasing $\mathrm{PM}_{2.5}$ concentrations to an increasing trend. The monthly average hourly fraction between the DFP and BASE scenario runs is $-12.0 \%$, and the mean hourly concentration fraction between DOU and BASE is $12.4 \%$. Located in the south of the WFC, Zhangjiakou is a downstream site in terms of the prevailing northwesterly winds during the wintertime. The increasing wind speed and momentum due to the downstream edge effect (rough to smooth underlying surface) could enhance the dispersion of $\mathrm{PM}_{2.5}$ and reduce concentration in Zhangjiakou City, characterized by the negative fraction (-12\% for monthly 
mean fraction). Doubling the WFC area virtually encircles Zhangjiakou City within the expanded WFC, deficit) that favours increasing $\mathrm{PM}_{2.5}$ concentration, particularly in the wake area of the WFC, characterized by the positive $\mathrm{PM}_{2.5}$ fractions.

However, in the summertime the monthly concentration fractions between the DOU and BASE model scenario simulations are lower than those of the DFP to BASE scenario simulations, which suggests that the expansion of WFC reduces $\mathrm{PM}_{2.5}$ concentrations in Zhangjiakou. This is because the doubled WFC area encircled Zhangjiakou within the WFC. Under the prevailing southeasterly summer monsoon (Figure S1), Zhangjiakou becomes an upstream site in the DFP case (not doubling WFC). Higher $\mathrm{PM}_{2.5}$ concentrations are conveyed from the severely contaminated Beijing-Tianjin-Hebei area, and the upstream edge effect (Mo et al., 2017) might slow down the wind speed and, as a result, enhance $\mathrm{PM}_{2.5}$ concentrations.

\section{Discussions}

The fluctuating $\mathrm{PM}_{2.5}$ within and around the WFC can be interpreted by atmospheric dynamics and thermodynamics. In addition to the wind farm "edge" effect owing to the horizontal step changes in underlying surface characteristics (Mo et al., 2017), the wind turbine rotors generated turbulence that could, on the one hand, produce eddies that increase the vertical mixing of momentum and thus, reduce the wind speed at the turbine hub-height level (Baidya Roy, 2004, 2011; Barrie and Kirk-Davidoff, 2010). On the other hand, the increasing vertical mixing could also increase the vertical mixing of scalars such as air temperature and air pollutants. There are statistically significant negative correlations between $\Delta \mathrm{PM}_{2.5}$ and $\Delta \mathrm{TKE}$ and between $\Delta \mathrm{PM}_{2.5}$ and $\Delta \mathrm{V}(\mathrm{V}$ is wind speed $)$, where $\Delta \mathrm{PM}_{2.5}$ indicates the difference between $\mathrm{PM}_{2.5}$ concentration from the WFC-related scenario simulations and the BASE scenario run; the same applies for $\Delta \mathrm{TKE}$ and $\Delta \mathrm{V}$. Figure $\mathbf{S 1 4}$ is a correlation diagram between $\Delta \mathrm{PM}_{2.5}$ and $\Delta \mathrm{TKE}$, and between $\Delta \mathrm{PM}_{2.5}$ and $\Delta \mathrm{V}$ in January 2016 within and downstream of the WFC, calculated by the differences of these three variables between the DFP and BASE scenario runs. The negative correlations can be seen both inside and outside the WFC, which clearly manifests that growing turbulence and wind speed from the WFC-related simulations reduced $\mathrm{PM}_{2.5}$ concentration compared with the no-WFC (BASE) simulation, and vice versa. 
We further estimated vertical cross sections of modelled monthly fractions $\mathrm{PM}_{2.5}$, TKE, air temperature, and wind speeds of the three WFC-related scenario runs (SRL, DFP, DOU) to the BASE run in January 2016 along the transect across the WFC and its downstream region, as shown by the solid green line in Figure S15, which also illustrates the monthly $\mathrm{PM}_{2.5}$ concentration difference between DFP and BASE (=DFP-BASE) in January 2016. Negative fractions can be readily identified in the immediate upstream region and within the WFC, and positive fractions are present in the downstream region, which indicates declining $\mathrm{PM}_{2.5}$ in the WFC and the increase of $\mathrm{PM}_{2.5}$ levels in the downstream of the WFC (Figure 2b). Vertically, we can observe negative $\mathrm{PM}_{2.5}$ concentration fractions at a relatively low level of the atmosphere within the WFC from the three WFC-related simulations that extend from the ground surface to approximately $100 \mathrm{~m}$ height (Figure 9a), which shows that WFC tends to reduce $\mathrm{PM}_{2.5}$ compared with its surroundings. Monthly TKE fractions between the three WFC-related model scenario runs and the BASE simulation illustrate a clear positive profile at and above the hub height within the WFC from all three WFC-related scenario simulations (Figure 9b), which confirms the increasing turbulence intensity driven by rotated wind turbine rotors. Compared with no-WFC (BASE) case, TKE in the WFC increased up to a factor of 5-6 as shown by the positive TKE fraction of 500\%-600\% (Figure 9b1-b3), and high TKE fractions extend from $150-800 \mathrm{~m}$ with the maximum at 300-400 $\mathrm{m}$ within the WFC. The increasing TKE throughout the ABL within the WFC is in line with Fitch et al.'s modelling results (2012) but their maximum TKE occurred between 100 and $150 \mathrm{~m}$ height, and the negative fraction in the hundred kilometre downstream of the WFC at a lower atmospheric level near the surface compared with the positive fraction within the WFC. Our result also illustrates clearly that the negative TKE fractions, indicting decreasing TKE in the presence of the WFC, extend hundred kilometres downstream of the WFC, again agreeing well with Fitch et al.'s simulations (2012). The negative wind speed fractions within the WFC with the maximum negative fractions at the turbine height (100-120 m) and wind speed deficit in the wake region are consistent with Fitch et al. (2012) as well. Both modelling results show negative wind speed differences between windfarm and no-windfarm scenario simulations from windfarms and their downwind regions of several hundred kilometres (Figure 9c1-c3). Note also a positive temperature fraction near the surface and the negative temperature fraction centred at the $500-\mathrm{m}$ height, which manifests increasing air temperatures near the surface and decreasing temperature at the relatively high elevation, agreeing to some extent with windfarm modelling result using large eddy simulations (Porté-Agel et al., 2014). The positive temperature fractions, manifesting increasing 
temperature, in the downwind region of the wind farms up to a thousand kilometre have been also reported previously (Wang and Prinn, 2010: Baidya Roy and Traiteur, 2010: Vautard et al. 2013; and Sun et al. 2017).

These vertical profiles provide insights into the understanding of the responses of $\mathrm{PM}_{2.5}$ to the presence of large-scale wind farms. As previously mentioned, the wind turbine-generated turbulence enhances the vertical mixing of momentum and scalars in the wind farm (Baidya Roy, 2004, 2011), which tends to weaken the momentum near the surface and enhance the momentum above the hub height. The conversion of kinetic energy to mechanical energy further reduces the wind speed at the hub height

(Figure 9c). The vertical profiles of air temperature in wind farms have been extensively investigated (Baidya Roy, 2004; Baidya Roy and Traiteur, 2010; Wang and Prinn, 2010; Zhou et al., 2012). These studies have shown marked effects on near surface temperatures from the increased vertical mixing owing to turbulence generated by wind turbine rotors. The increasing temperatures near the surface overlaid by decreasing temperatures aloft (Figure 9d) imply a negative lapse rate associated with an unstable boundary-layer, which leads to stronger vertical mixing, which in turn enhances vertical diffusion of $\mathrm{PM}_{2.5}$ and, as a result, reduces concentrations of $\mathrm{PM}_{2.5}$ near the surface (Figure 9a).

The negative TKE fractions centred near the southern boundary of the WFC at a relatively lower level compared with its positive fraction within the WFC suggests weakening turbulent activities and mixing that reduces $\mathrm{PM}_{2.5}$ vertical mixing and diffusion and thus results in higher $\mathrm{PM}_{2.5}$ concentrations downstream of the WFC (Figure 9a and 9d). The positive $\Delta \mathrm{PM}_{2.5}$ vertical profiles indicate enhanced $\mathrm{PM}_{2.5}$ concentration approximately $600 \mathrm{~km}$ to the south (downstream) of the WFC, as shown in Figure 9a, seem to agree to some extent with the perturbations in regional temperature and other weather conditions forced by large-scale wind farm arrays that are hundreds and thousands of kilometres distant from wind farm installations (Barrie and Kirk-Davidoff, 2010; Vautard et al., 2014). A close look at

Figure 9a can also identify relatively large values of $\Delta \mathrm{PM}_{2.5}$ in the southern boundary and immediately downstream of the WFC. Wang and Prinn (2010) and Keith et al. (2004) have reported that temperature perturbations induced by a large-scale land installation of wind turbines can spread well outside the installation regions. As aforementioned, our results show that both $\Delta \mathrm{V}$ and $\Delta \mathrm{T}$ profiles within the WFC extend to the downstream of the WFC. The negative $\Delta \mathrm{V}$ within the WFC is extended to its southern 
the immediate downstream of the WFC can be clearly observed. Among the windfarms in northern China, the area covered by the WFC in Hebei Province alone is more than $5250 \mathrm{~km}^{2}$ and likely forms a long distance wind deficit wake to the downstream. As a result, the weak wind speed favours the accumulation of $\mathrm{PM}_{2.5}$ concentrations, characterized by higher $\mathrm{PM}_{2.5}$ concentrations. The turbulence activities induced by the steep surface roughness changes might also play an important role. The rough-to-smooth surface transition from the WFC to its downstream leads to the reduction of the friction velocity and turbulent intensity, which could otherwise reduce the vertical mixing of $\mathrm{PM}_{2.5}$ concentrations and result in higher $\mathrm{PM}_{2.5}$ concentrations near the surface.

\section{Conclusions}

Extensive model sensitivity simulations using the WRF-Chem model were conducted to assess the effect of large-scale wind farms in northern China on $\mathrm{PM}_{2.5}$ and air quality forecasts in the NCP, the region most contaminated by $\mathrm{PM}_{2.5}$ in China. We quantified the perturbations of hourly and monthly $\mathrm{PM}_{2.5}$ concentrations induced by a large-scale WFC in typical winter and summer months across western Inner Mongolia, northern Hebei Province, and the border region between eastern Inner Mongolia and Jilin Province. We show that the WFC tends to increase $\mathrm{PM}_{2.5}$ levels in its downstream regions. Our modelling results revealed that the WFC enhanced the $\mathrm{PM}_{2.5}$ level in northeast Hebei Province by $49 \%$ in the wintertime (January) and $12 \%$ in Zhangiiakou in the summertime (July), the places adjacent to the WFC. The model scenario simulations with and without the presence of WFC yielded strong hourly concentration fractions and perturbations, which indicates the marked influences of WFC on the $\mathrm{PM}_{2.5}$ environmental fate and forecasting. The WFC more significantly perturbs the $\mathrm{PM}_{2.5}$ air concentrations in the wintertime than in the summertime, which is associated with prevailing and local wind fields and with the wind speed deficit wake and "edge" effect. We argue that the wind turbine rotor-generated TKE enhances the vertical mixing of $\mathrm{PM}_{2.5}$, which reduces its level near the surface of the WFC. The wind deficit wake and weak TKE extending to the downstream of the WFC might increase $\mathrm{PM}_{2.5}$ levels.

The marked changes in $\mathrm{PM}_{2.5}$ concentration forced by the WFC in its inside and downstream regions manifest that the influences of large-scale wind farms on air quality forecasts and emissions mitigation should not be overlooked. Severe haze pollution characterized by elevated concentrations of $\mathrm{PM}_{2.5}$ in the Beijing-Tianjin-Hebei region has received widespread concern in the Chinese government and the 

the causes of $\mathrm{PM}_{2.5}$ formation. For example, China's State Council issued the "Action Plan on Prevention and Control of Air Pollution" in 2013, which requests that the most stringent measures are taken to control haze (SCC, 2013). The Action Plan aimed to reduce $\mathrm{PM}_{2.5}$ in the Beijing-Tianjin-Hebei region by $25 \%$ in 2017 compared to 2012 levels. In September 2018, the Ministry of Ecology and Environment of China issued a new action plan to control air pollution in the Beijing-Tianjin-Hebei region and its surrounding areas (MEPC, 2018), which requests that further refined management measures be taken to reduce $\mathrm{PM}_{2.5}$ levels and to develop more accurate modelling tools to predict the air quality in this region. It is likely that the WFC and its future expansion under the national clean energy development plan (Dai et al., 2018; Sahu et al., 2018) would bring additional difficulties in the air quality forecasting and national strategy to reduce $\mathrm{PM}_{2.5}$ in the Beijing-Tianjin-Hebei region. More studies should be conducted to pinpoint the levels, intensities, and locations of $\mathrm{PM}_{2.5}$ perturbations induced by large-scale wind farms.

Supplement. The Supplement related to this article is available online. X.Z., and J.D. collected the measured data to validate the model. J.M., S.L., and T.H. analyzed the data, interpreted the results, and drafted the manuscript. Other authors participated in the acquisition, analysis, or interpretation of data.

Acknowledgements. This work is funded by the National Natural Science Foundation of China through grant U1806207, 41977357, 41877507, and the National Key R\&D Program of China through grant 2017 YFC0212002.

\section{References}

Ackermann, I. J., Hass, H., Memmesheimer, M., Ebel, A., Binkowski, F. S., and Shankar, U.: Modal aerosol dynamics model for Europe, Atmos. Environ., 32, 2981-2999, 10.1016/s13522310(98)00006-5, 1998.

Baidya Roy, S.: Can large wind farms affect local meteorology? J. Geophys. Res., 109, 1-6, 
Baidya Roy, S., and Traiteur, J. J.: Impacts of wind farms on surface air temperatures, Proc. Natl. Acad. Sci. USA., 107, 17899-17904, 10.1073/pnas.1000493107, 2010.

Baidya Roy, S.: Simulating impacts of wind farms on local hydrometeorology, J. Wind. Eng. Ind. Aerod., 99, 491-498, 10.1016/j.jweia.2010.12.013, 2011.

Barrie, D. B., and Kirk-Davidoff, D. B.: Weather response to a large wind turbine array, Atmos. Chem. Phys., 10, 769-775, 10.5194/acp-10-769-2010, 2010.

Borbon, A., Gilman, J. B., Kuster, W. C., Grand, N., Chevaillier, S., Colomb, A., Dolgorouky, C., Gros, V., Lopez, M., Sarda-Esteve, R., Holloway, J., Stutz, J., Petetin, H., McKeen, S., Beekmann, M., Warneke, C., Parrish, D. D., and de Gouw, J. A.: Emission ratios of anthropogenic volatile organic compounds in northern mid-latitude megacities: Observations versus emission inventories in Los Angeles and Paris, J. Geophys. Res-Atmos., 118, 2041-2057, 10.1002/jgrd.50059, 2013.

Bossioli, E., Tombrou, M., Kalogiros, J., Allan, J., Bacak, A., Bezantakos, S., Biskos, G., Coe, H., Jones, B. T., Kouvarakis, G., Mihalopoulos, N., and Percival, C. J.: Atmospheric composition in the Eastern Mediterranean: Influence of biomass burning during summertime using the WRF-Chem model, Atmos. Environ., 132, 317-331, 10.1016/j.atmosenv.2016.03.011, 2016.

Cervarich, M. C., Roy, S. B., and Zhou, L. M.: Spatiotemporal structure of wind farm-atmospheric boundary layer interactions, Energy. Procedia., 40, 530-536, 10.1016/j.egypro.2013.08.061, 2013.

Christiansen, M. B., and Hasager, C. B.: Wake effects of large offshore wind farms identified from satellite SAR, Remote. Sens. Environ., 98, 251-268, 10.1016/j.rse.2005.07.009, 2005. assessment, Renew. Sust. Energ. Rev., 97, 156-164, 10.1016/j.rser.2018.08.044, 2018.

EAC (The Energy Administration of the People's Republic of China): The Thirteenth Five-Year Plan for Wind Energy Development. Available at: http://www.nea.gov.cn/2016-11/29/c_135867633.htm (last access: 12 June 2019).

Fiedler, B. H., and Bukovsky, M. S.: The effect of a giant wind farm on precipitation in a regional climate model, Environ. Res. Lett., 6, 045101, 10.1088/1748-9326/6/4/045101, 2011.

Fitch, A. C., Olson, J. B., Lundquist, J. K., Dudhia, J., Gupta, A. K., Michalakes, J., and Barstad, I.: Local and Mesoscale Impacts of Wind Farms as Parameterized in a Mesoscale NWP Model, Mon. Weather. Rev., 140, 3017-3038, 10.1175/Mwr-D-11-00352.1, 2012. 
Fitch, A. C., Lundquist, J. K., and Olson, J. B.: Mesoscale Influences of Wind Farms throughout a Diurnal

Cycle, Mon. Weather. Rev., 141, 2173-2198, 10.1175/Mwr-D-12-00185.1, 2013.

Fitch, A. C.: Notes on using the mesoscale wind farm parameterization of Fitch et al. (2012) in WRF,

Wind Energy, 19, 1757-1758, https://doi.org/10.1002/we.1945, 2015.

Frandsen, S., Barthelmie, R., Pryor, S., Rathmann, O., Larsen, S., Højstrup, J., and Thøgersen, M.:

10.1002/we.189, 2006.

Global Wind Energy Council: Global Wind Report 2016: Annual market update. Available at

http://www.indianwindpower.com/pdf/GWEC_Global_Wind_2016_Report.pdf.

Guenther, A. B., Jiang, X., Heald, C. L., Sakulyanontvittaya, T., Duhl, T., Emmons, L. K., and Wang, X.:

The Model of Emissions of Gases and Aerosols from Nature version 2.1 (MEGAN2.1): an extended and updated framework for modeling biogenic emissions, Geosci. Model. Dev., 5, 1471-1492, 10.5194/gmd-5-1471-2012, 2012.

Ivanova, L. A., and Nadyozhina, E. D.: Numerical Simulation of Wind Farm Influence on Wind Flow, J. Wind. Eng. Ind. Aerod., 24, 257-269, 10.1260/0309524001495620, 2000. turbine wakes at the wind farm resolving scale: a composite-based analysis with the Weather Research and Forecasting model over Horns Rev, Wind Energy, 18, 559-566, 10.1002/we.1708, 2015.

Keith, D. W., Decarolis, J. F., Denkenberger, D. C., Lenschow, D. H., Malyshev, S. L., Pacala, S., and

Rasch, P. J.: The influence of large-scale wind power on global climate, Proc. Natl. Acad. Sci. USA., 101, 16115-16120, 10.1073/pnas.0406930101, 2004.

Kirk-Davidoff, D. B., and Keith, D. W.: On the climate impact of surface roughness anomalies, J. Atmos. Sciences., 65, 2215-2234, 10.1175/2007jas2509.1, 2008.

Lettau, H.: Note on Aerodynamic Roughness-Parameter Estimation on the Basis of Roughness-Element

Description, J. Appl. Meteorol. Clim., 8, 828-832, 10.1175/15200450(1969)008<0828:Noarpe >2.0.Co;2, 1969.

Lee, J. C. Y., and Lundquist, J. K.: Evaluation of the wind farm parameterization in the Weather Research and Forecasting model (version 3.8.1) with meteorological and turbine power data, Geosci. Model Dev., 10, 4229-4244, 10.5194/gmd-10-4229-2017, 2017. 
585 Li, M., Zhang, Q., Kurokawa, J., Woo, J. H., He, K. B., Lu, Z. F., Ohara, T., Song, Y., Streets, D. G., Carmichael, G. R., Cheng, Y. F., Hong, C. P., Huo, H., Jiang, X. J., Kang, S. C., Liu, F., Su, H., and Zheng, B.: MIX: a mosaic Asian anthropogenic emission inventory under the international collaboration framework of the MICS-Asia and HTAP, Atmos. Chem. Phys., 17, 935-963, 10.5194/acp-17-935-2017, 2017.

Climate model shows large-scale wind and solar farms in the Sahara increase rain and vegetation, Science, 361, 1019-1022, 10.1126/science.aar5629, 2018.

Lu, X., Hong, J. Y., Zhang, L., Cooper, O. R., Schultz, M. G., Xu, X. B., Wang, T., Gao, M., Zhao, Y. H., and Zhang, Y. H.: Severe Surface Ozone Pollution in China: A Global Perspective, Environ. Sci. Tech. Let., 5, 487-494, 10.1021/acs.estlett.8b00366, 2018.

McElroy, M. B., Lu, X., Nielsen, C. P., and Wang, Y.: Potential for wind-generated electricity in China, Science, 325, 1378-1380, 10.1126/science.1175706, 2009.

Mo, J., Huang, T., Zhang, X., Zhao, Y., Liu, X., Li, J., Gao, H., and Ma, J.: Spatiotemporal distribution of nitrogen dioxide within and around a large-scale wind farm - a numerical case study, Atmos. Chem. Phys., 17, 14239-14252, 10.5194/acp-17-14239-2017, 2017.

MEPC (Ministry of Environmental Protection of China): Air pollution control plan issued for BeijingTianjin-Hebei in fall, winter. Available at: http://www.china.org.cn/china/201809/28/content 64258840.htm (last access: 12 Sep 2019) 2018.

Petersen, R. L.: A wind tunnel evaluation of methods for estimating surface roughness length at industrial facilities, Atmos. Environ., 31, 45-57, 10.1016/S1352-2310(96)00154-9, 1997.

Porté-Agel, F., Lu, H., and Wu, Y.-T.: Interaction between Large Wind Farms and the Atmospheric Boundary Layer, Procedia IUTAM, 10, 307-318, 10.1016/j.piutam.2014.01.026, 2014.

Sahu, B. K.: Wind energy developments and policies in China: A short review, Renew. Sust. Energ. Rev., 81, 1393-1405, 10.1016/j.rser.2017.05.183, 2018.

SCC (The State Council of the People's Republic of China): Air pollution and control action plan. Available at: http://www.gov.cn/zwgk/2013-09/12/conent_2486773.htm (last access: 10 Sep 2019) 2013.

Sun, H. W., Luo, Y., Zhao, Z. C., and Chang, R.: The Impacts of Chinese Wind Farms on Climate, J. Geophys. Res-Atmos., 123, 5177-5187, 10.1029/2017jd028028, 2018. 

chemical composition, aerosol optical properties and their relationships across China, Atmos. Chem. Phys., 17, 9485-9518, 10.5194/acp-17-9485-2017, 2017.

Vautard, R., Thais, F., Tobin, I., Breon, F. M., Devezeaux de Lavergne, J. G., Colette, A., Yiou, P., and Ruti, P. M.: Regional climate model simulations indicate limited climatic impacts by operational and planned European wind farms, Nat. Commun., 5, 3196, 10.1038/ncomms4196, 2014.

Volker, P., Badger, J., Hahmann, A. N., and Ott, S.: Wind Farm parametrization in the mesoscale model WRF. In Proceedings European Wind Energy Association (EWEA), 2012.

Wang, C., and Prinn, R. G.: Potential climatic impacts and reliability of very large-scale wind farms, Atmos. Chem. Phys., 10, 2053-2061, 10.5194/acp-10-2053-2010, 2010. Been Exacerbated by Terrain and Meteorological Conditions, Bull. Am. Meteorol. Soc., 99, $105-$ 119, 10.1175/bams-d-16-0301.1, 2018.

Wiedinmyer, C., Akagi, S. K., Yokelson, R. J., Emmons, L. K., Al-Saadi, J. A., Orlando, J. J., and Soja, A. J.: The Fire INventory from NCAR (FINN): a high resolution global model to estimate the emissions from open burning, Geosci. Model. Dev., 4, 625-641, 10.5194/gmd-4-625-2011, 2011.

Wieringa, J.: Representative Roughness Parameters for Homogeneous Terrain, Bound-lay. Meteorol., 63, 323-363, 10.1007/Bf00705357, 1993.

Xia, G., Zhou, L. M., Freedman, J. M., Roy, S. B., Harris, R. A., and Cervarich, M. C.: A case study of effects of atmospheric boundary layer turbulence, wind speed, and stability on wind farm induced temperature changes using observations from a field campaign, Clim. Dynam., 46, 2179-2196, 10.1007/s00382-015-2696-9, 2016.

Xia, G., Cervarich, M. C., Roy, S. B., Zhou, L. M., Minder, J. R., Jimenez, P. A., and Freedman, J. M.: Simulating Impacts of Real-World Wind Farms on Land Surface Temperature Using the WRF Model: Validation with Observations, Mon. Weather. Rev., 145, 4813-4836, 10.1175/Mwr-D-160401.1, 2017.

Xu, R., Tang, G., Wang, Y., and Tie, X.: Analysis of a long-term measurement of air pollutants (20072011) in North China Plain (NCP); Impact of emission reduction during the Beijing Olympic Games, Chemosphere, 159, 647-658, 10.1016/j.chemosphere.2016.06.025, 2016. 
https://doi.org/10.5194/acp-2019-991

Preprint. Discussion started: 25 March 2020

(c) Author(s) 2020. CC BY 4.0 License.

Yuan, R., Ji, W., Luo, K., Wang, J., Zhang, S., Wang, Q., Fan, J., Ni, M., and Cen, K.: Coupled wind

645 farm parameterization with a mesoscale model for simulations of an onshore wind farm, Applied Energy 206, 113-125, 2017.

Zhao, B., Wang, S., Wang, J., Fu, J. S., Liu, T., Xu, J., Fu, X., and Hao, J.: Impact of national NOx and SO2 control policies on particulate matter pollution in China, Atmos. Environ., 77, 453-463, 10.1016/j.atmosenv.2013.05.012, 2013.

650 Zhou, L., Tian, Y., Baidya Roy, S., Thorncroft, C., Bosart, L. F., and Hu, Y.: Impacts of wind farms on land surface temperature, Nat. Clim. Change., 2, 539-543, 10.1038/nclimate1505, 2012. 


\section{Figure Captions}

Figure 1. Nested model domains and installed power. d01 is the outer domain entirely covering northern China and d02 is the inner domain covering part of Inner Mongolia, the NCP, and surroundings. The areas with red colour shading highlight major large-scale wind farms (WFC) in northern China. Red pentagram, black squares, and triangles represent Beijing (BIJ), Zhangjiakou (ZJK), and Tianjin (TIJ), respectively. Two blank elliptical circles represent northeast (NHB) and central (CHB) Hebei province.

Figure 2. Modelled monthly averaged $\mathrm{PM}_{2.5}$ concentration fractions between WFC-related model scenarios and the BASE scenario in January 2016 in the inner model domain. (a) Monthly mean concentration fractions between SLR (S2) model run and BASE (S1) simulation; (b) same as Figure 2a but for the fraction between DFP (S3) and BASE (S1) simulations; (c) same as Figure 2a but for the fraction between DOU (S4) and BASE (S1) simulations. $\mathrm{PM}_{2.5}$ fractions are calculated by $f_{i}=\left(\mathrm{C}_{\mathrm{Si}}-\mathrm{C}_{\mathrm{BASE}}\right)$ $\times 100 / \mathrm{C}_{\mathrm{BASE}}$. The areas where the monthly $\mathrm{PM}_{2.5}$ fractions are significant at the $95 \%$ confidence level $(t$ test) are highlighted by the black dots. Grey shading areas denote the location of the WFC.

Figure 3. (a) WRF-Chem modelled fractions (\%) of hourly $\mathrm{PM}_{2.5}$ concentrations in January 2016 from SRL simulation to that from the BASE simulation in northeast and central Hebei Province (NHB, CHB), Beijing (BEJ), Tianjin (TIJ), and Zhangjiakou (ZJK). (b) Monthly average hourly $\mathrm{PM}_{2.5}$ concentrations over January 2016 in the five selected regions and cities. The locations of these five regions and cites are marked in Figure 1.

Figure 4. Modelled fractions of $\mathrm{PM}_{2.5}$ concentration near the surface, the differences of winds $\left(\mathrm{m} \mathrm{s}^{-1}\right)$, and fractions of TKE $\left(\mathrm{m}^{2} \mathrm{~s}^{-2}\right)$ at the hub height (the fourth level of WRF-Chem) between the DFP and BASE model scenario simulations at 0700 LST January 3 (maximum positive fractions) and 1500 LST January 16 (maximum negative fractions), 2016. a and b. $\mathrm{PM}_{2.5}$ fractions at 0700 LST January 3 (maximum positive fractions) and 1500 LST January 16 (maximum negative fraction), 2016; $\mathbf{c}$ and $\mathbf{d}$, the same as Figure $\mathbf{4 a}$ and $\mathbf{4 b}$ but for wind speed differences; $\mathbf{e}$ and $\mathbf{f}$, the same as Figure $\mathbf{4 a}$ and $\mathbf{4 b}$ but for TKE fractions. 
Figure 5. Modelled monthly averaged $\mathrm{PM}_{2.5}$ concentration and concentration differences between WFCrelated model scenarios and the BASE scenario in July 2016. (a) Monthly mean concentration from BASE (S1) simulation; (b) $\mathrm{PM}_{2.5}$ concentration differences between SRL (S2) and BASE (S1) simulations; (c) same as Figure 5b but for the differences between DFP (S3) and BASE (S1) simulations; (d) same as Figure 5b but for DOU (S4) and BASE (S1) simulations. $\mathrm{PM}_{2.5}$ differences are calculated by $\left(\mathrm{C}_{\mathrm{Si}}-\mathrm{C}_{\mathrm{BASE}}\right)$, where $\mathrm{C}_{\mathrm{Si}}$ denotes modelled concentrations from different model scenarios $(\mathrm{i}=2,3,4)$. The areas where the monthly $\mathrm{PM}_{2.5}$ fractions are significant at the $95 \%$ confidence level (t-test) are highlighted by the black dots.

Figure 6. WRF-Chem simulated hour concentration fractions of $\mathrm{PM}_{2.5}$ from model scenario SRL to that from the control run in the five selected regions and cities in July 2016 (a), and monthly averaged concentration fractions in the selected places in July 2016 (b). The geographic location of these five regions are shown in Figure 1. Error bars indicate \pm 1 standard deviation.

Figure 7. Modelled $\mathrm{PM}_{2.5}$ concentration fractions in daytime and nighttime averaged over January 2016. (a) the monthly averaged concentration of $\mathrm{PM}_{2.5}$ during the daytime (0700-1800 LST); (b) the monthly averaged concentration of $\mathrm{PM}_{2.5}$ during the nighttime (1900-0600 LST); (c), (d), (e) the monthly averaged concentration fractions of $\mathrm{PM}_{2.5}$ during the daytime between WFC-related (SRL, DFP, DOU) model scenarios and the BASE scenario simulations; (f), (g), (h) the same as Figure 7c-e but for the nighttime cases. Regions where the $\mathrm{PM}_{2.5}$ fractions exhibit $95 \%$ confidence level calculated by the contrast experiment $t$-test (Method section) are highlighted with black dots. The grey area indicates the WFC locations.

Figure 8. Modelled hourly $\mathrm{PM}_{2.5}$ concentration fractions between DOU and DFP scenario runs and the BASE scenario run in Zhangjiakou City in January 2016.

Figure 9. Vertical cross-sections of modelled fractions [(DOU-BASE) $\times 100 / \mathrm{BASE}$ ] of monthly $\mathrm{PM}_{2.5}$ concentration (a), TKE (b), wind speed (c), and air temperature (d) between the three WFC-related model scenarios of SRL (left panel), DFP (mid panel), and DOU (right panel) and the BASE model scenario run in January 2016 along the transect across the WFC, bounded by the black dashed line, and its 
https://doi.org/10.5194/acp-2019-991

Preprint. Discussion started: 25 March 2020

(C) Author(s) 2020. CC BY 4.0 License.

downstream, as shown in the solid green arrow line in Figure S15. 
https://doi.org/10.5194/acp-2019-991

Preprint. Discussion started: 25 March 2020

(c) Author(s) 2020. CC BY 4.0 License.

(c) (i)
Atmospheric

Chemistry and Physics

Discussions

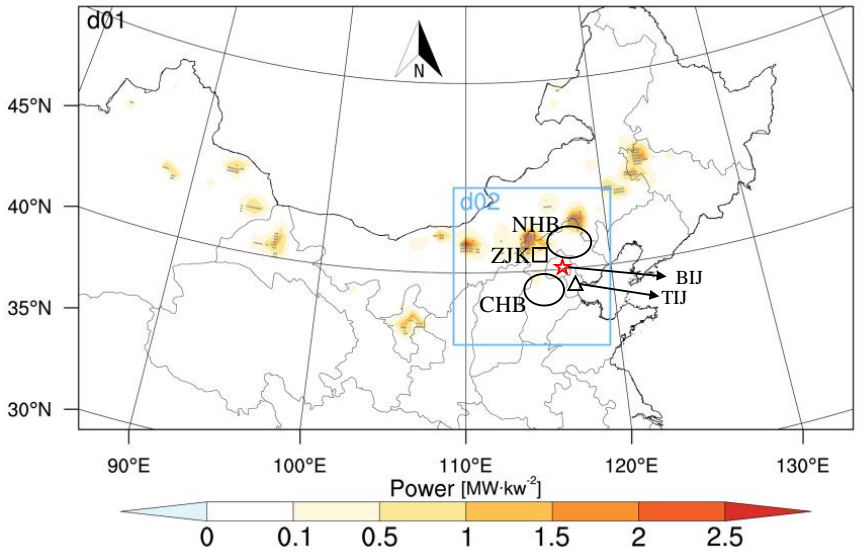

Figure 1 
https://doi.org/10.5194/acp-2019-991

Preprint. Discussion started: 25 March 2020

(c) Author(s) 2020. CC BY 4.0 License.
Atmospheric

Chemistry and Physics

Discussions a

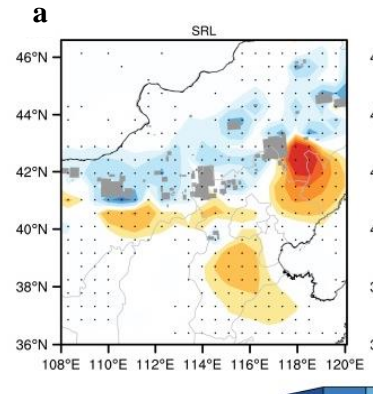

b

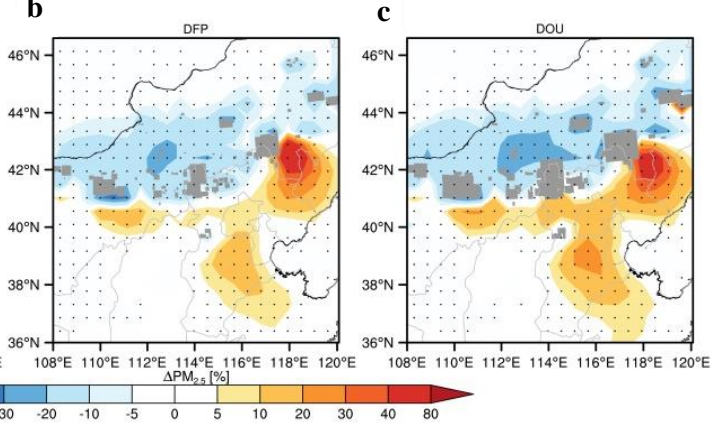

Figure 2 
https://doi.org/10.5194/acp-2019-991

Preprint. Discussion started: 25 March 2020

(c) Author(s) 2020. CC BY 4.0 License.
Atmospheric

Chemistry and Physics

Discussions
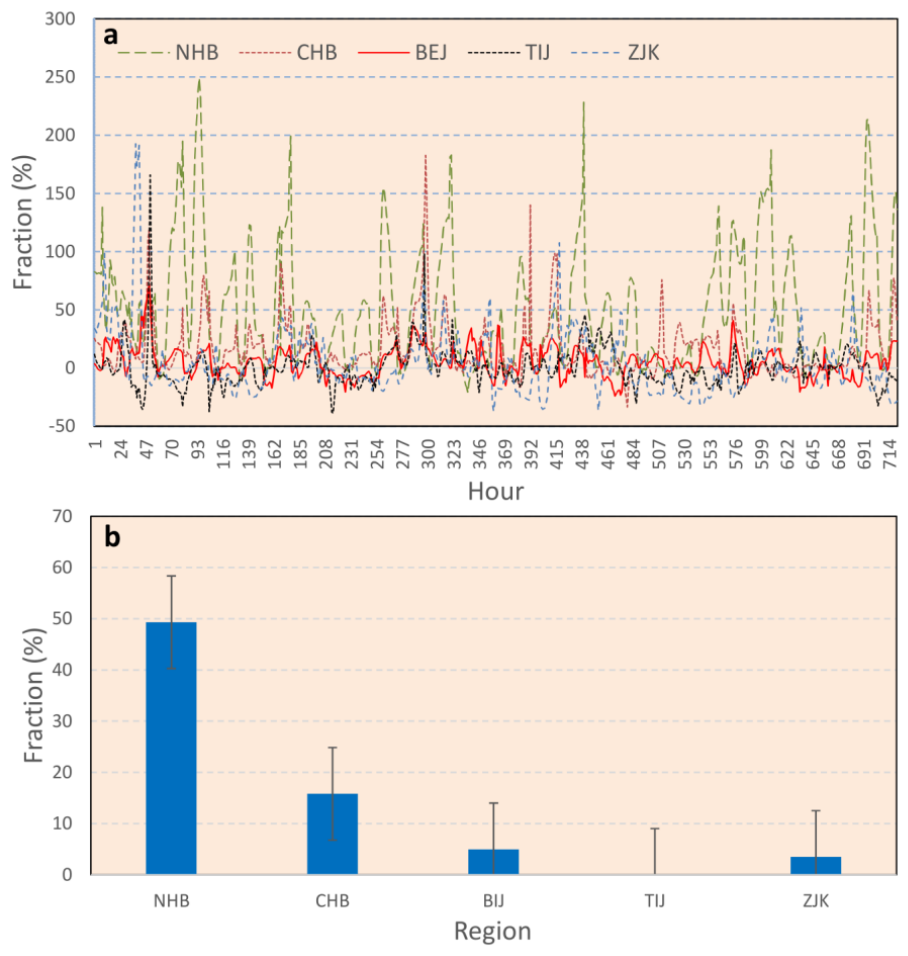

Figure 3 
https://doi.org/10.5194/acp-2019-991

Preprint. Discussion started: 25 March 2020

(c) Author(s) 2020. CC BY 4.0 License.
Atmospheric Chemistry and Physics

Discussions
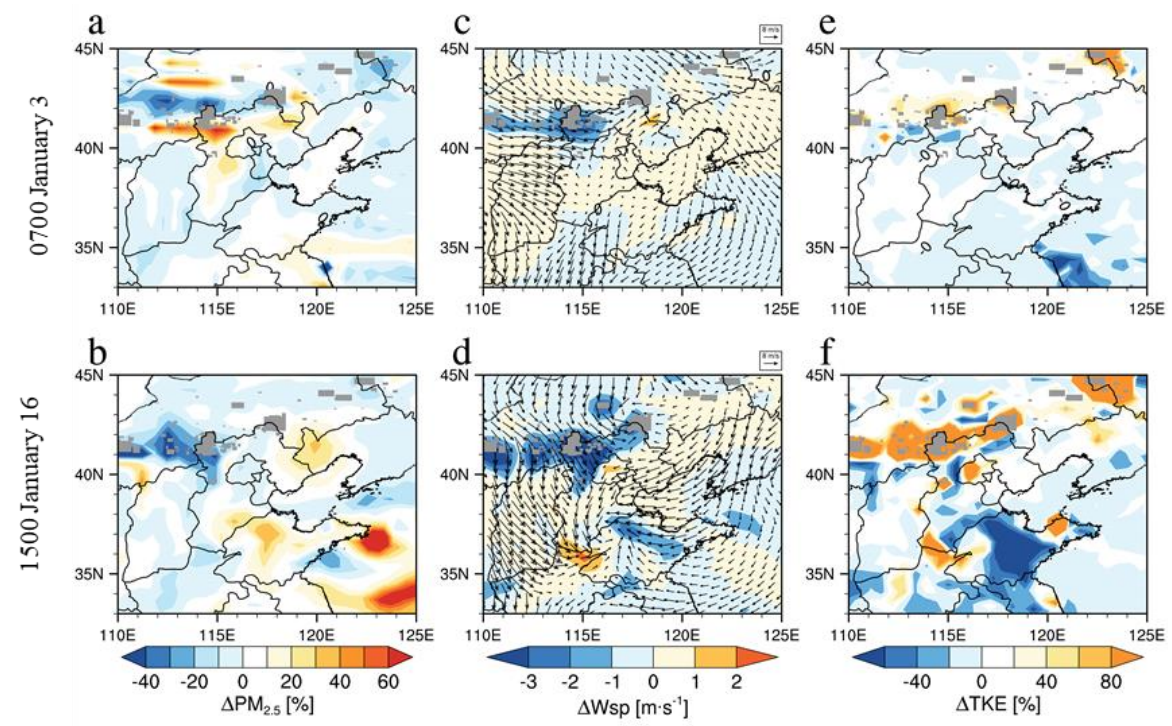

d
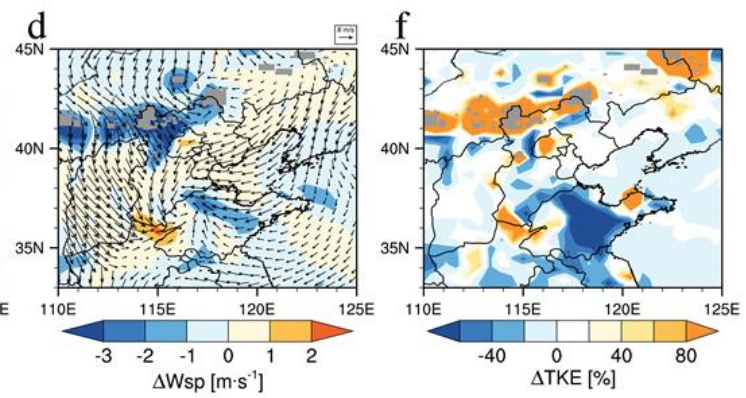

Figure 4 
https://doi.org/10.5194/acp-2019-991

Preprint. Discussion started: 25 March 2020

(c) Author(s) 2020. CC BY 4.0 License.
Atmospheric

Chemistry and Physics

Discussions a

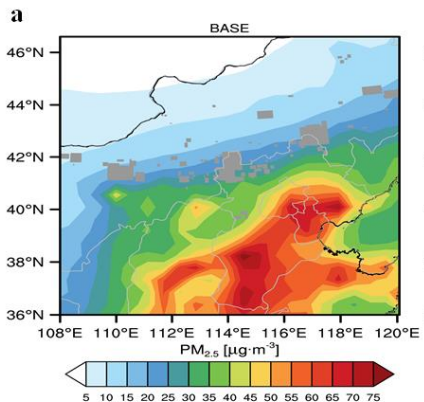

c

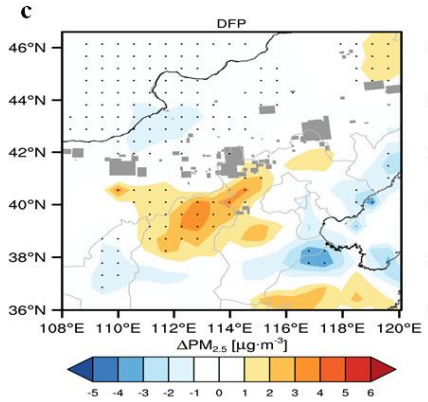

b

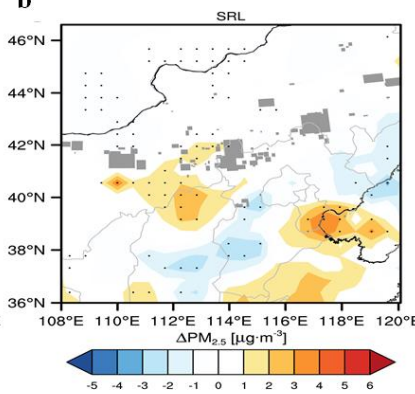

d

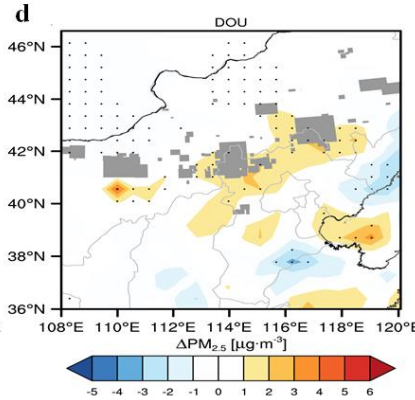

Figure 5 
https://doi.org/10.5194/acp-2019-991

Preprint. Discussion started: 25 March 2020

(c) Author(s) 2020. CC BY 4.0 License.
Atmospheric

Chemistry and Physics

Discussions
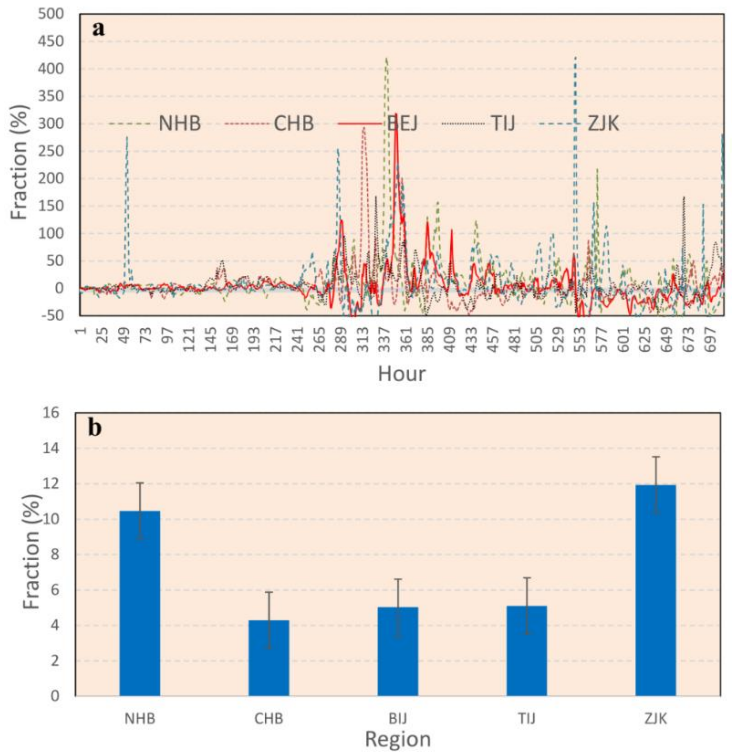

Figure 6 
https://doi.org/10.5194/acp-2019-991

Preprint. Discussion started: 25 March 2020

(c) Author(s) 2020. CC BY 4.0 License.
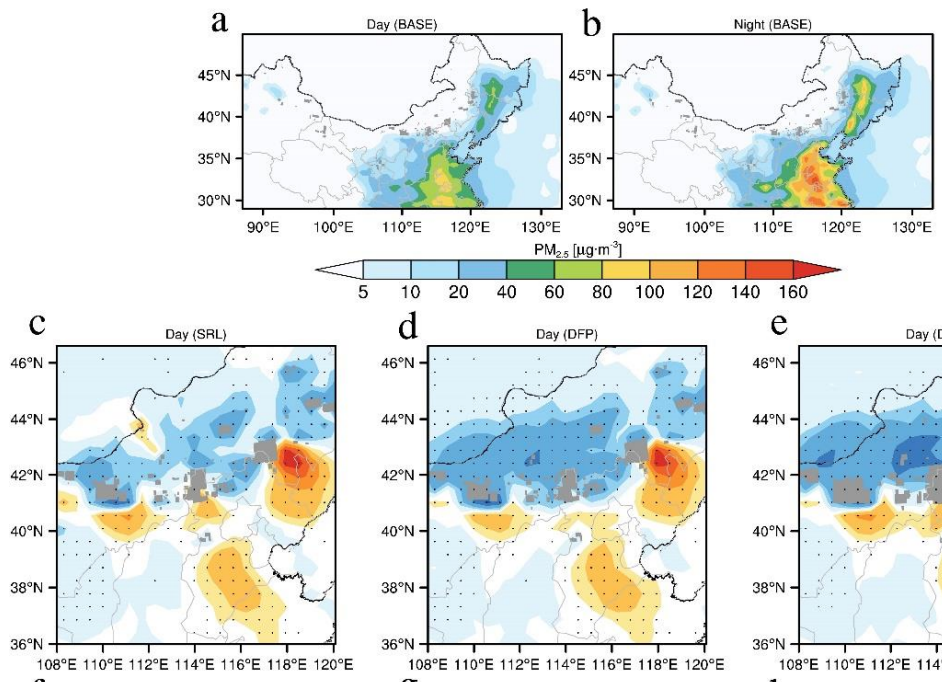

e Day (DOU)
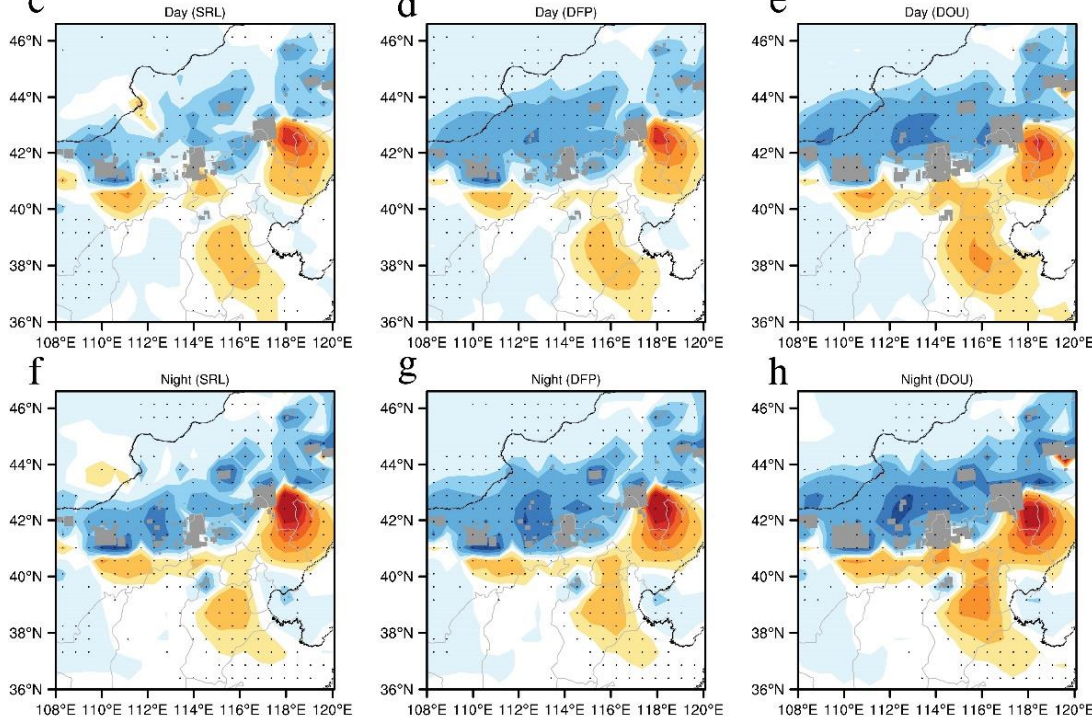

h

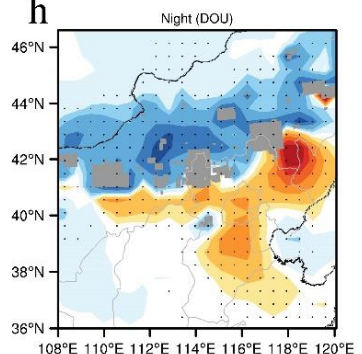

$\triangle P M_{25}[\%]$

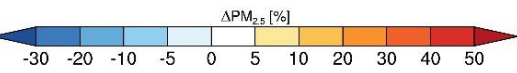

Figure 7 
https://doi.org/10.5194/acp-2019-991

Preprint. Discussion started: 25 March 2020

(C) Author(s) 2020. CC BY 4.0 License.

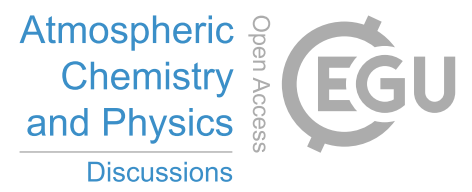

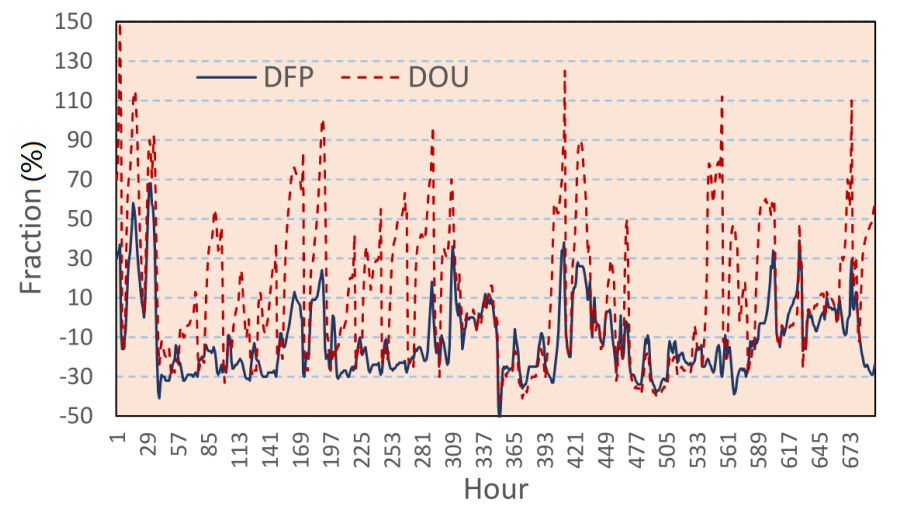

Figure 8 
https://doi.org/10.5194/acp-2019-991

Preprint. Discussion started: 25 March 2020

(c) Author(s) 2020. CC BY 4.0 License.
Atmospheric

Chemistry and Physics

Discussions

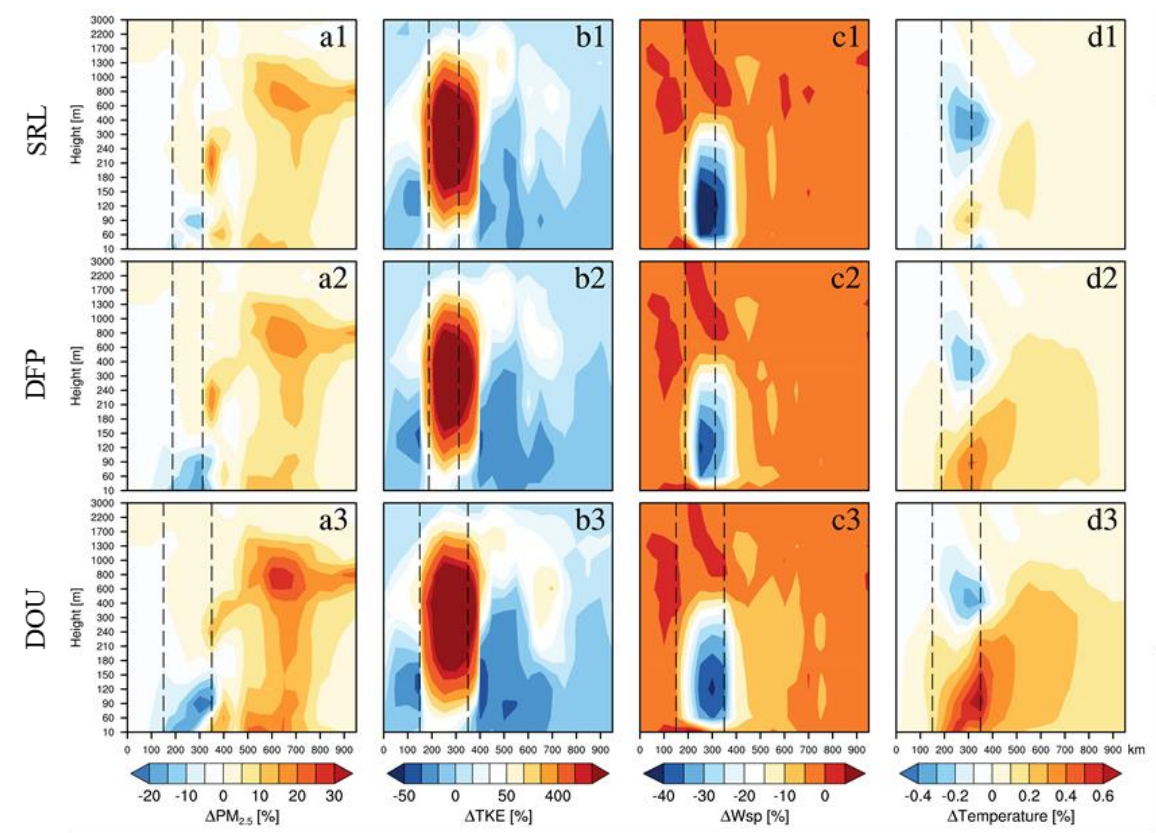

Figure 9 